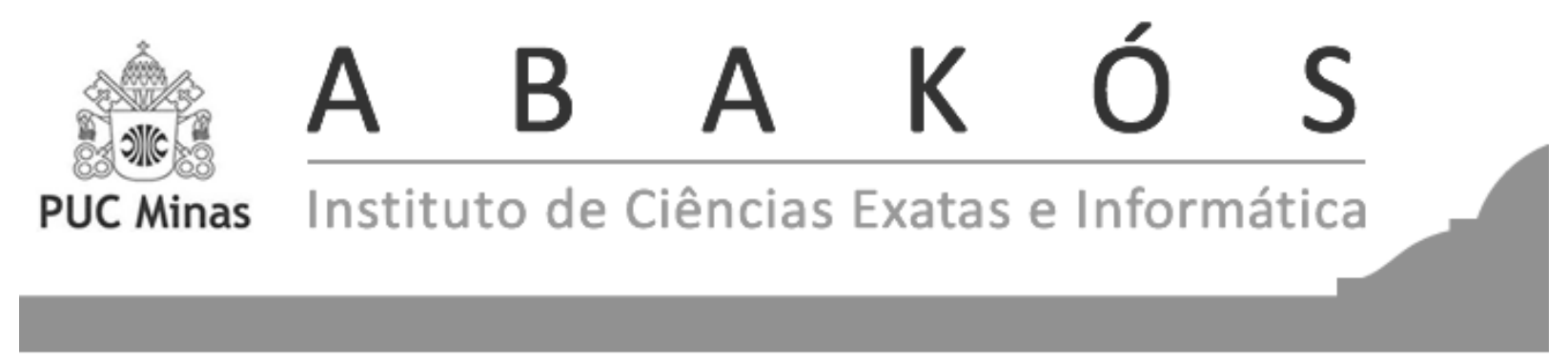

\title{
Sistema para Controle de Velocidade de uma Esteira Transportadora Industrial*
}

System for Speed Control of an Industrial Conveyor

Flávia Gonçalves Fernandes ${ }^{1}$ Erivan de Paula Santos Neto ${ }^{2}$

\begin{abstract}
Resumo
Dentre as muitas atribuições de um engenheiro eletricista, o controle de sistemas é uma tarefa primordial para o sucesso de um negócio. Esse gerenciamento é fundamental para garantir o controle da produção, reduzir custos, evitar prejuízos e visar lucros. No entanto, gerenciar sistemas de controle é um desafio que pode consumir muito tempo do gestor, inviabilizando outras ações de extrema importância para a produtividade e o crescimento da empresa. Para facilitar esse trabalho, o mercado tem desenvolvido e aperfeiçoado programas que possibilitam esse controle de forma mais simples e funcional. Nessa perspectiva, esse trabalho tem como objetivo utilizar fundamentos de sistemas de controle para ajustar a velocidade desejada de uma esteira transportadora industrial. Para isso, também foram inseridos controladores com ações independentes no sistema: do tipo proporcional $(\mathrm{P})$, proporcional-integral (PI), proporcional-derivativo (PD) e proporcional-integral-derivativo (PID), apresentando os resultados obtidos a partir do desempenho do sistema para cada um dos casos, com suas respectivas discussões e conclusões.
\end{abstract}

Palavras-chave: Função de transferência. Sistema de controle. Velocidade.

\footnotetext{
*Submetido em 09/01/2019 - aceito em 18/02/2021.

${ }^{1}$ Docente EBTT do Instituto Federal de Educação, Ciência e Tecnologia de Mato Grosso do Sul - Campus Dourados - Área: Informática. Doutoranda em Ciências Exatas e Tecnológicas na Universidade Federal de Catalão. Biomédica, Mestre em Engenharia Biomédica pela Universidade Federal de Uberlândia. Bacharel em Engenharia da Computação pela Universidade de Uberaba. Catalão - GO, Brasil- flavia.fernandes@ifms.edu.br

${ }^{2}$ Mestre em Modelagem e Otimização pela Universidade Federal de Catalão. Bacharel em Engenharia Civil pela Universidade Federal de Catalão. Catalão - GO, Brasil- erivandepaula@gmail.com
} 


\begin{abstract}
Among the many assignments of an electrical engineer, system control is a prime task for the success of a business. This management is essential to ensure production control, reduce costs, avoid losses, and target profits. However, managing control systems is a challenge that can be time-consuming for the manager, making other actions of extreme importance for productivity and company growth unfeasible. To facilitate this work, the market has developed and perfected software that enables this control in a simpler and more functional way. In this perspective, this work aims to use the fundamentals of control systems to adjust the desired speed of an industrial conveyor belt. For this, we also inserted controllers with independent actions in the system: proportional (P), proportional-integral (PI), proportional-derivative (PD), and proportional-integral-derivative (PID), presenting the results obtained from the performance of the system for each case, with their respective discussions and conclusions.
\end{abstract}

Keywords: Transfer function. Control system. Speed. 


\section{INTRODUÇÃO}

Um sistema de controle é uma interconexão de vários componentes resultando em uma configuração que fornece um desempenho desejado (OGATA, 2011). A descrição do sistema se refere à relação causal entre a entrada e a saída do sistema, em geral, descrita matematicamente através de equações diferenciais, equações de diferença, funções de transferência (LEONARDI, 2010). Assim, o sinal de entrada deve ser controlado tal que o sinal de saída possua um comportamento desejado (NISE, 2002).

Em indústrias que possuem sistemas de controle, muitos fatores podem contribuir para não ser possível se alcançar os objetivos de desempenho: a complexidade do controlador se refere a topologia da estrutura de controle e ao grau dos polinômios utilizados para implementar o controlador; a utilização de estruturas de controle com complexidade polinomial predefinida (BEGA, 2006).

Além disso, usualmente, sistemas de controle sofrem a ação de distúrbios, tais como atrito e folgas, por exemplo. Tais distúrbios podem ser representados como sinais de entrada no sistema que afetam diretamente a planta a ser controlada (LEONARDI, 2010).

Um sistema de controle em malha aberta utiliza um dispositivo atuador para controlar o processo diretamente sem a utilização de realimentação (feedback). Dessa forma, o sistema de controle não sabe qual o valor do sinal de saída (variável controlada). Porém, em malha fechada, a interação entre a entrada e a saída permite realocar os polos e zeros do sistema de tal forma a tentar satisfazer os requisitos desejados (BINGHAM; DAVIES, 2007).

A ideia fundamental do projeto de sistemas de controle é alterar as características do sistema no domínio do tempo e, consequentemente, no domínio da frequência através da introdução de um controlador (FIALHO, 2012).

Os modelos de planta utilizados para o projeto de sistemas de controle são apenas aproximações da planta real, e comumente, os mais simples possíveis. Optando-se com frequência por modelos lineares invariantes no tempo representados por funções de transferência com polinômios de baixa ordem (NISE, 2002). Para isso, despreza-se comportamentos não lineares e parâmetros variantes no tempo quando esses não são significativos (CHAPMAN, 2003).

Neste contexto, o objetivo deste trabalho consiste em desenvolver um sistema de controle para a velocidade de uma esteira transportadora industrial de maneira que o sistema de bombeamento consiga manter uma taxa de vazão qi constante, e o motor DC acione a esteira suprindo a vazão de saída qo para alimentar a usina de processamento. Além disso, inseriu-se um controlador com ações independentes no sistema, do tipo proporcional (P), proporcionalintegral (PI), proporcional-derivativo (PD) e proporcional-integral-derivativo (PID), apresentando o desempenho do sistema para cada um dos casos e as respectivas conclusões. 


\section{DESENVOLVIMENTO}

Este trabalho consiste, em desenvolver um sistema de controle para a velocidade de uma esteira. A Figura 1 apresenta um sistema de transporte de massa utilizando um sistema eletromecânico composto por motor DC, polias e esteira.

\section{Figura 1 - Modelo do sistema da esteira}

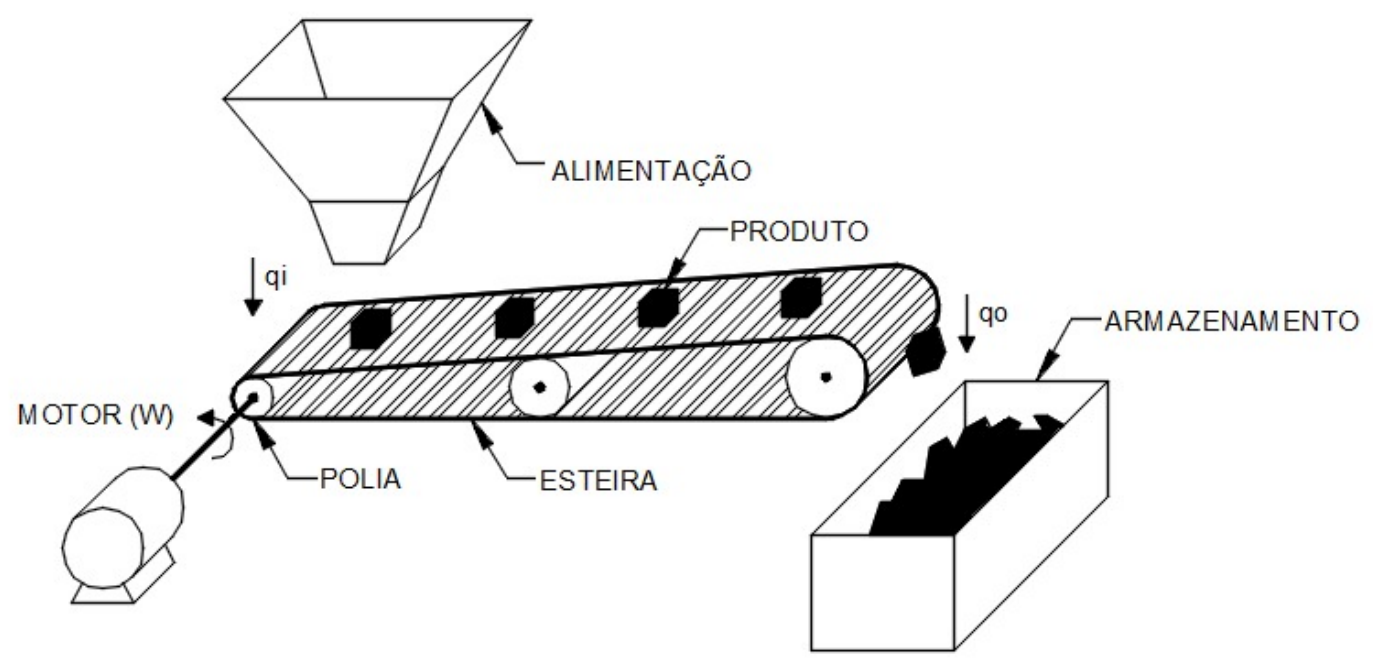

Fonte: Autoria própria.

O produto (massa $\mathrm{M}$ ) é depositado sobre a esteira e transportado até uma usina de processamento a 100 metros de distância, onde serve de matéria prima para a fabricação de um composto químico. O sistema de bombeamento consegue manter uma taxa de vazão qi constante, e o motor DC aciona a esteira suprindo a vazão de saída qo para alimentar a usina de processamento. Para que o sistema funcione a contento, o controle de velocidade da esteira tem que ser preciso.

Este trabalho faz uma análise detalhada de vários tipos de controladores P, PI, PD e PID e realiza uma comparação entre os mesmos, o que é um diferencial em relação a outros trabalhos já disponíveis na literatura, como encontrado em (NOGUEIRA, 2004; DIAS et al., 2008; DIAS, 2012; RANIEL, 2011; FREITAS et al., 2013). Esses autores tratam desses tipos de controladores separadamente, sem efetuar a comparação entre os sistemas de controle disponíveis e utilizados.

Para determinar experimentalmente um modelo matemático para o sistema composto pelo motor, acoplamento, esteira e massa, foi feito um ensaio ao degrau, em malha aberta, alimentado pelo motor CC com uma tensão de 100 volts, com a finalidade de registrar a variação de velocidade da esteira. A finalidade é a obtenção do melhor ajuste possível para que a esteira seja mantida em velocidade constante, sem oscilação.

Nessa perspectiva, um sistema de primeira ordem é representado matematicamente por equações diferenciais lineares ordinárias de primeira ordem, conforme apresentado na Equação 
1.

$$
\frac{C(s)}{U(s)}=\frac{k}{\tau . s+1}
$$

em que o ganho é representado pela letra $\mathrm{k}$, a constante de tempo é representada pela letra $\tau$, $\mathrm{U}(\mathrm{s})$ representa a função de transferência relacionada à entrada de dados e $\mathrm{C}(\mathrm{s})$ à saída de dados.

Com a aplicação de $100 \mathrm{~V}$ na entrada U(s), obteve-se 50 como valor de saída C(s), como pode ser visto na Equação 2.

$$
K=\text { Ganho }=\frac{\text { sada }}{\text { entrada }}=\frac{50}{100}=0,5
$$

A saída é proporcional ao sinal de erro (diferença entre entrada e realimentação), de modo que o atuador opera continuamente, com potência variável. O controlador é simplesmente um amplificador. Esse sistema é ainda simples e de baixo custo, tendo uma precisão boa, mas nem sempre é rápido, e pode se tornar instável, se o ganho for muito alto. Instabilidade é a situação em que o controlador reage muito rápido, e a saída passa do valor na entrada sem que haja a reversão da tendência, o que pode levar à saturação do amplificador, ou à oscilação contínua em torno do valor na entrada (geração de onda senoidal na saída, sem entrada).

Na Figura 2, é apresentado o modelo matemático de primeira ordem utilizado para realizar a simulação por meio do Simulink, que é um toolbox do software MATLAB.

Figura 2 - Modelo Matemático de $\mathbf{1}^{\text {a }}$ ordem

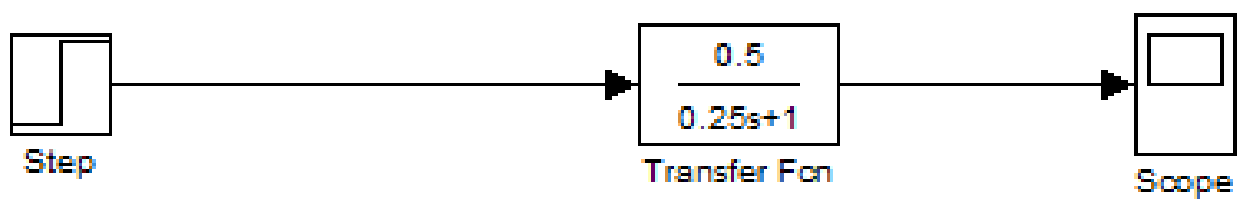

Fonte: Autoria própria.

Aplicando um sinal degrau na entrada de 100 volts o sistema responderá de acordo com a curva mostrada na Figura 3, similar ao gráfico de uma função logarítmica. 


\section{Figura 3 - Resposta da velocidade do motor $1^{\text {a }}$ de ordem}

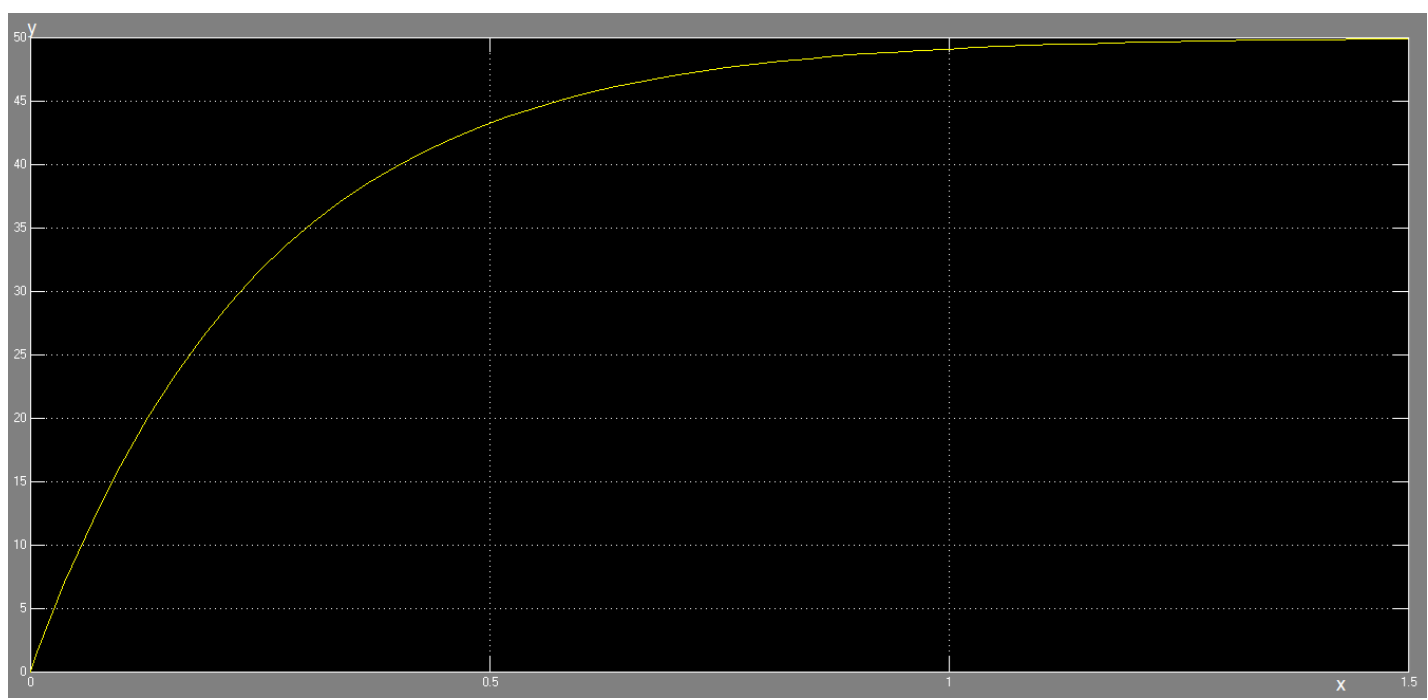

Fonte: Autoria própria.

Considerando que o ganho do sistema é k e t é o tempo, e assumindo que a resposta esperada (no gráfico) ao degrau $\mathrm{u}(\mathrm{t})=1$ seria $\mathrm{c}(\mathrm{t})=\mathrm{k}$ em regime permanente, pode-se definir $\mathrm{o}$ erro de resposta ao degrau como sendo a diferença entre a resposta esperada $(\mathrm{c}(\mathrm{t}))$ e a resposta real, ou seja:

$$
\begin{gathered}
e(t)=k \cdot u(t)-c(t) \\
e(t)=k-k\left(1-e^{\frac{-t}{\tau}}\right) \\
e(t)=k \cdot e^{\frac{-t}{\tau}}
\end{gathered}
$$

Portanto, à medida que t aumenta, o erro em relação ao valor esperado tenderá a zero. Isso ocorre após vencido o regime transitório.

Um sistema de segunda ordem pode ser representado pelo modelo matemático mostrado na Equação 4, onde $\zeta$ (zeta) é o coeficiente de amortecimento do sistema.

$$
\frac{C(s)}{R(s)}=\frac{k \cdot \omega_{n}^{2}}{s^{2}+2 \cdot \zeta \cdot \omega_{n} \cdot s+\omega_{n}^{2}}
$$

$\mathrm{Na}$ Figura 4, é apresentado o modelo matemático de $2^{\mathrm{a}}$ ordem utilizado para realizar a simulação.

O sistema de $1^{\mathrm{a}}$ ordem contém apenas um bloco controlador no fluxograma, e o de $2^{\mathrm{a}}$ ordem possui dois blocos. Geralmente, o sistema de $2^{\mathrm{a}}$ ordem realiza a otimização do sistema de controle de forma mais efetiva e eficaz em relação ao de $1^{\mathrm{a}}$ ordem. De qualquer forma, neste trabalho, está sendo realizada a comparação entre os dois sistemas com a finalidade de verificar essa informação obtida na literatura. 


\section{Figura 4 - Modelo matemático de $2^{\mathrm{a}}$ ordem}

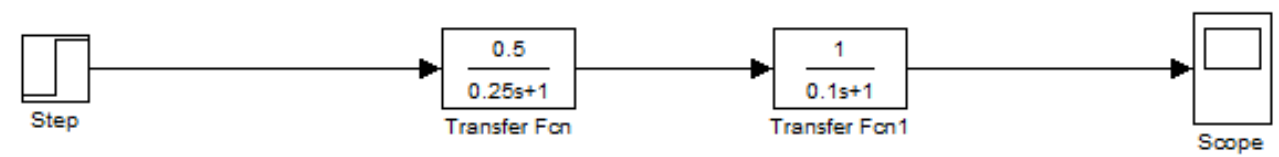

Fonte: Autoria própria.

Aplicando um sinal degrau na entrada de 100 volts o sistema responderá de acordo com a Figura 5, similar ao gráfico de uma função logarítmica. Isso demonstra que os resultados para os sistemas de $1^{\mathrm{a}}$ e $2^{\mathrm{a}}$ ordem são similares, uma vez que o gráfico de ambos apresenta um comportamento próximo.

\section{Figura 5 - Resposta de $2^{\mathrm{a}}$ ordem da velocidade do motor}

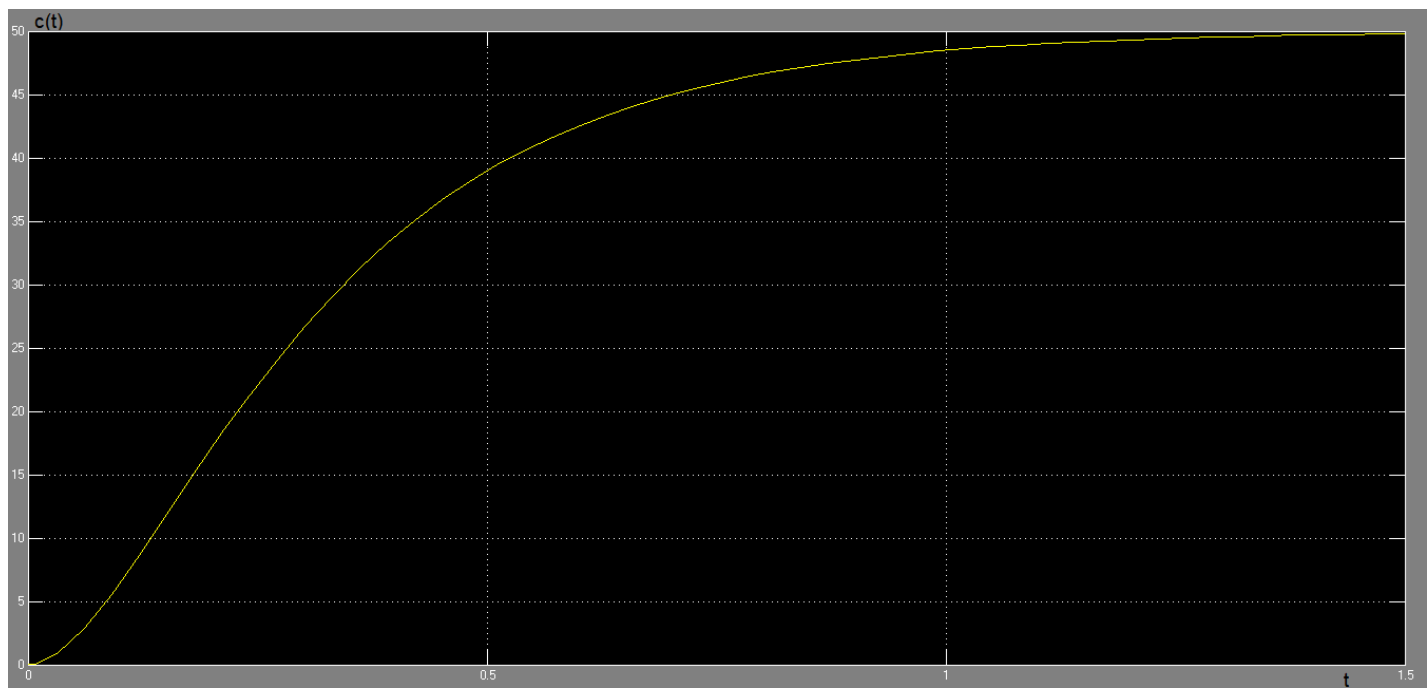

Fonte: Autoria própria.

Tipos de respostas de sistemas de segunda ordem (OGATA, 2011):

- Subamortecida: um polo na origem proveniente da entrada degrau unitário e dois polos complexos, provenientes do sistema. O gráfico de resposta é composto pelo decaimento exponencial gerado pela parte real do par de polos complexos, e a oscilação senoidal é gerada pela parte imaginária do par de polos complexos.

- Não-amortecida: um polo na origem proveniente da entrada degrau unitário e dois polos imaginários provenientes do sistema.

- Criticamente amortecida: um polo na origem proveniente da entrada degrau unitário e dois polos reais iguais. 
- Superamortecida: um polo na origem proveniente da entrada degrau unitário e dois polos reais.

Simulando os sistemas de $1^{\mathrm{a}}$ e $2^{\mathrm{a}}$ ordem concomitantemente, têm-se o modelo matemático mostrado na Figura 6.

Figura 6 - Modelo matemático de $1^{\text {a }}$ e de $2^{\text {a }}$ ordem

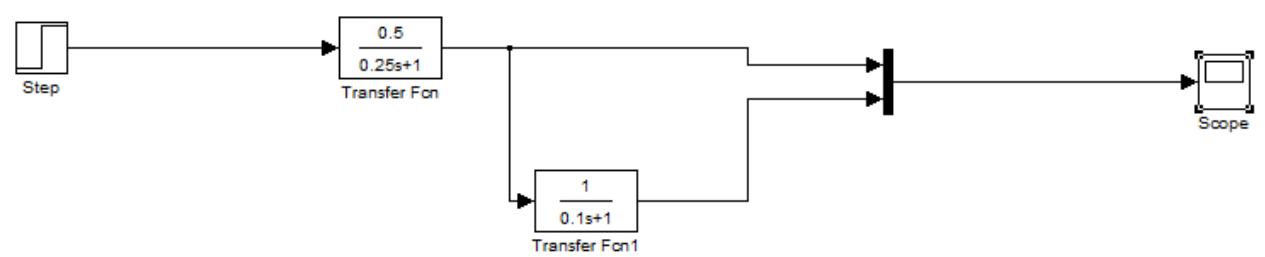

Fonte: Autoria própria.

Desse modo, o gráfico obtido é o apresentado na Figura 7, onde a primeira curva (em amarelo) representa o sistema de $1^{\mathrm{a}}$ ordem, e a segunda curva (em lilás) representa o sistema de $2^{\mathrm{a}}$ ordem.

\section{Figura 7 - Gráfico de $1^{\mathrm{a}}$ e de $2^{\mathrm{a}}$ ordem}

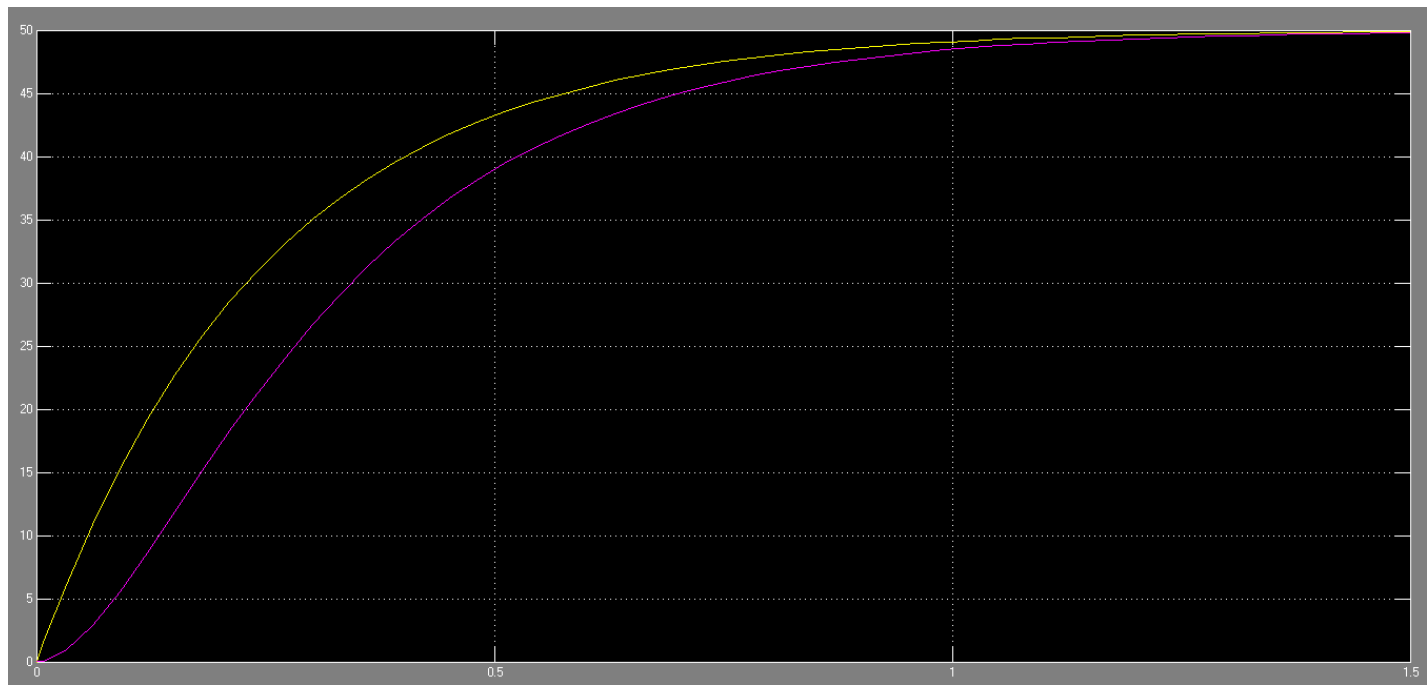

Fonte: Autoria própria.

Os gráficos acima foram feitos através da ferramenta Simulink, contida no software MATLAB. À medida que o fator de amortecimento (que considera a razão entre a frequência de decaimento exponencial da envoltória e a frequência natural do sistema; na prática, é o valor que acompanha o valor de s na função de transferência) aumentar, maior será o tempo de acomodação ou de estabilidade do sistema.

De acordo com os modelos da velocidade da esteira como saída apresentados anteriormente e observando os seus respectivos gráficos, pode-se concluir que não é possível controlar a 
velocidade utilizando um sistema em malha aberta, pois o sistema não conseguiu atingir o valor desejado de 100 V. Além disso, o sistema em malha aberta não possui realimentação (feedback), o que impossibilita o seu controle.

\subsection{SIMULAÇÃO CONTROLE EM MALHA FECHADA}

\subsubsection{CONTROLADOR PROPORCIONAL}

A Figura 8 mostra o diagrama de blocos em função do ganho Kp do controlador proporcional.

Figura 8 - Modelo com controlador Proporcional

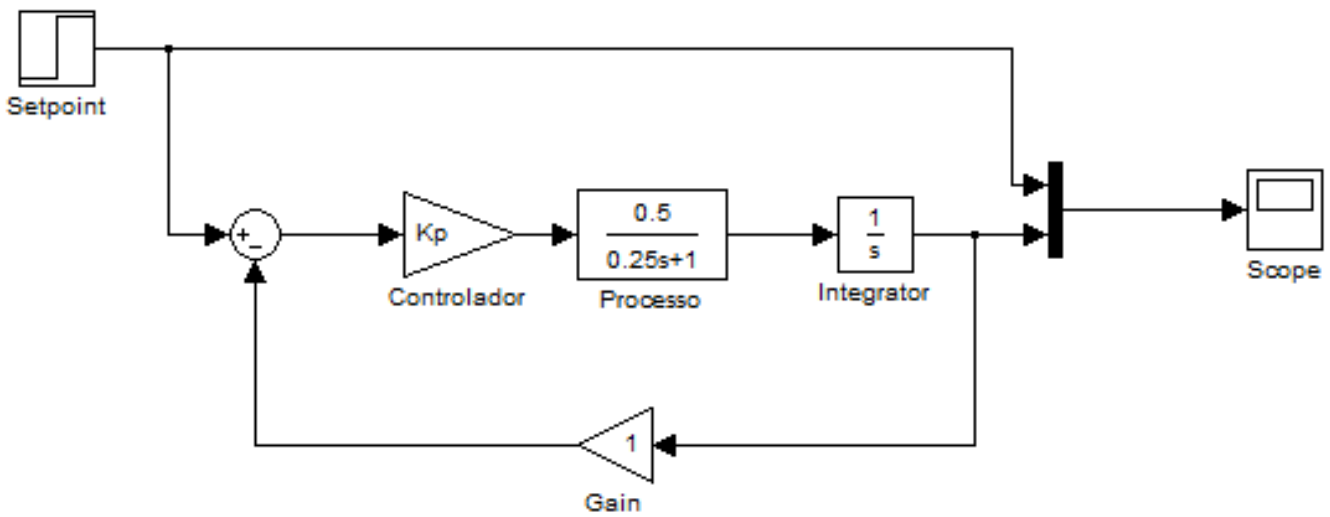

Fonte: Autoria própria.

A função de transferência para o modelo com controlador proporcional da Equação 5 é dado por:

$$
\begin{gathered}
\frac{C(s)}{R(s)}=\frac{\frac{0,5 K p}{0,25 s^{2}+s}}{1+\frac{0,5 K p}{0,25 s^{2}+s}}=\frac{\frac{0,5 K p}{0,25 s^{2}+s}}{\frac{0,25 s^{2}+s+0,5 K p}{0,25 s^{2}+s}}=\frac{0,5 K p}{0,25 s^{2}+s+0,5 K p} \\
\frac{C(s)}{R(s)}=\frac{2 K p}{s^{2}+4 s+2 K p} \\
\zeta=\frac{2}{\sqrt{2 K p}}
\end{gathered}
$$

- O sistema é criticamente amortecido para $\mathrm{Kp}=2$;

- O sistema é subamortecido para $\mathrm{Kp}>2$;

- O sistema é sobreamortecido para $\mathrm{Kp}<2$. 
A Figura 9 mostra a simulação em diagrama de blocos do sistema de controle de malha fechada, para três valores de Kp, de modo que ele seja classificado em cada um dos tipos de sistemas com amortecimento. Na Figura 10 é apresentado o gráfico obtido a partir dessa simulação de resposta ao degrau.

Figura 9 - Modelo com controlador proporcional igual a 1, 2 e 10

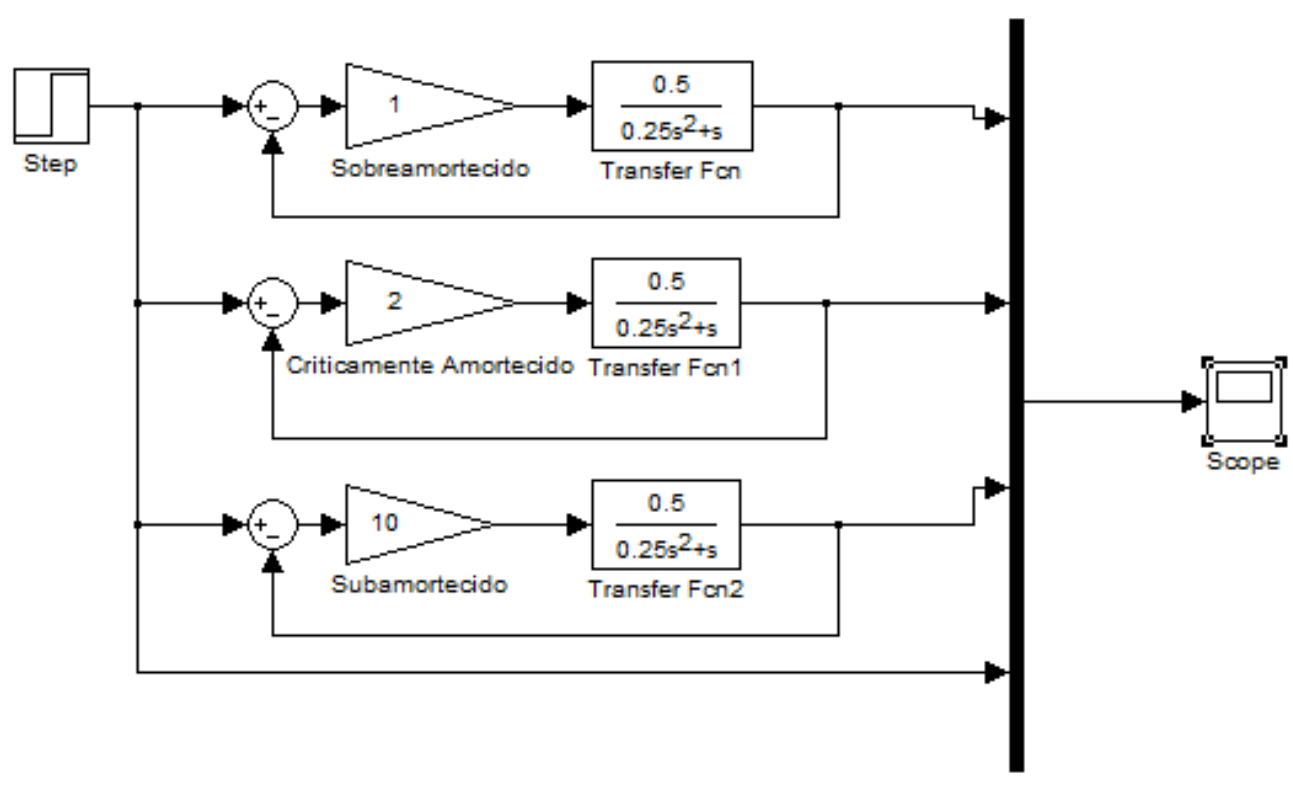

Fonte: Autoria própria.

Figura 10 - Gráfico do modelo com controlador proporcional igual a 1, 2 e 10, ordenadas respectivamente

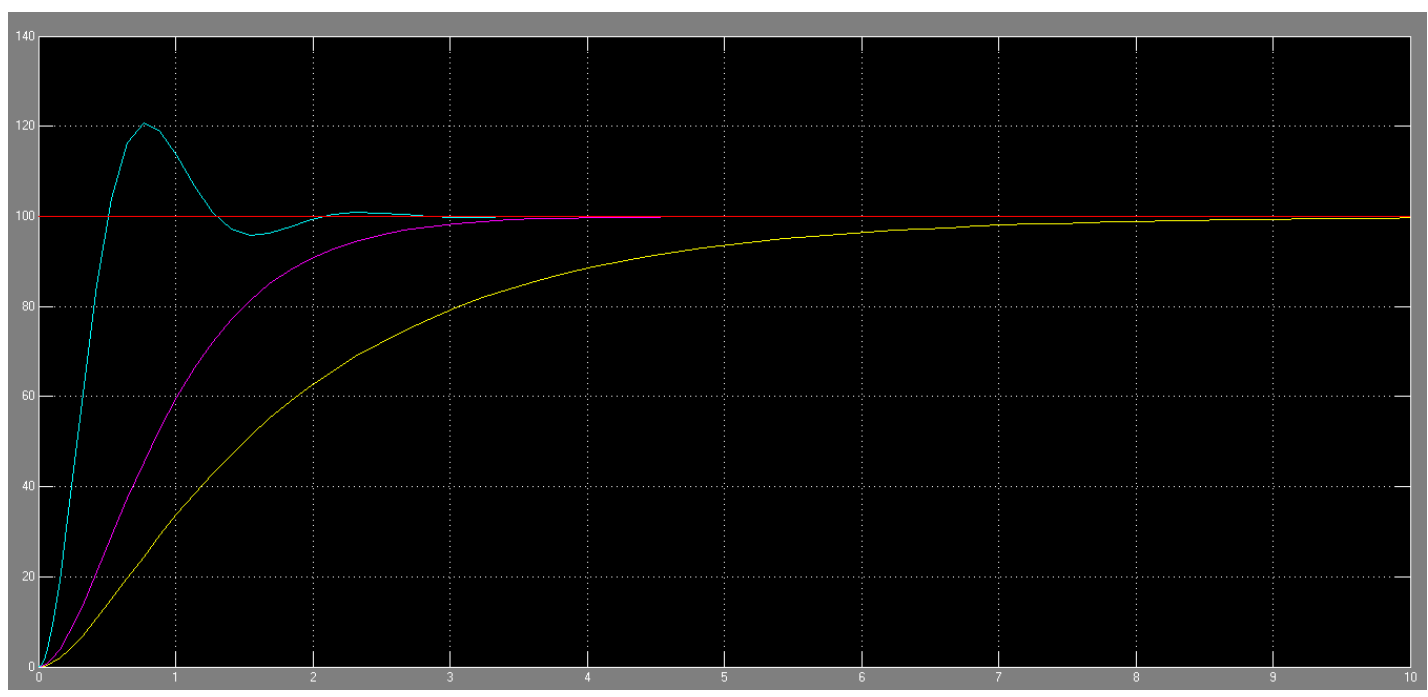

Fonte: Autoria própria. 
Dessa forma:

- A reta horizontal (vermelha) do gráfico representa a entrada do sistema com amplitude 100.

- A segunda curva (azul) representa um sistema subamortecido $(0<$ zeta $<1)$ com $\mathrm{Kp}=10$. Logo, sua função de transferência é:

$$
\frac{C(s)}{R(s)}=\frac{20}{s^{2}+4 s+20}
$$

E sua resposta no domínio do tempo é:

$$
c(t)=5 e^{-2 t} \cdot \operatorname{sen}(4 t)
$$

$\zeta=0,82 ; \mathrm{wn}=\sqrt{20} ; \mathrm{Wd}=1,4 ; \mathrm{MO}=10,1 ; \mathrm{Ss}=0,1 ; \mathrm{ts}=2,49 \mathrm{~s}$

- A terceira curva (lilás) representa um sistema criticamente amortecido (zeta $=1$ ) com $\mathrm{Kp}=2$. Logo, sua função de transferência é:

$$
\frac{C(s)}{R(s)}=\frac{4}{s^{2}+4 s+4}
$$

E sua resposta no domínio do tempo é:

$$
c(t)=4 t e^{-2 t}
$$

$\zeta=1 ; \mathrm{wn}=2 ; \mathrm{Wd}=0 ; \mathrm{MO}=2 ; \mathrm{Ss}=0 ; \mathrm{ts}=2,5 \mathrm{~s}$

- A quarta curva (amarela) representa um sistema sobreamortecido (zeta > 1) com $\mathrm{Kp}=1$. Logo, sua função de transferência é:

$$
\frac{C(s)}{R(s)}=\frac{2}{s^{2}+4 s+2}
$$

E sua resposta no domínio do tempo é:

$$
\begin{gathered}
c(t)=0,7 \cdot\left(e^{-0,6 t}-e^{-3,4 t}\right) \\
\zeta=1,41 ; \mathbf{w n}=\sqrt{2} ; \mathbf{W d}=1,41 ; \mathrm{MO}=1,01 ; \mathrm{Ss}=0,01 ; \mathrm{ts}=2,51 \mathrm{~s}
\end{gathered}
$$

O Método do Lugar das Raízes (M.L.R.) é uma técnica gráfica que permite visualizar de que forma os polos de um sistema em malha fechada variam quando se altera o valor de um parâmetro específico, que geralmente corresponde ao ganho (OGATA, 2011).

Além disso, este sistema monitorado por controlador proporcional foi analisado pelo método do lugar das raízes, cujo gráfico pode ser visualizado na Figura 11. 
Este método é bastante útil, pois permite fazer a análise de estabilidade de um sistema realimentado, de forma gráfica.

\section{Figura 11 - Gráfico do lugar das raízes para controlador proporcional}

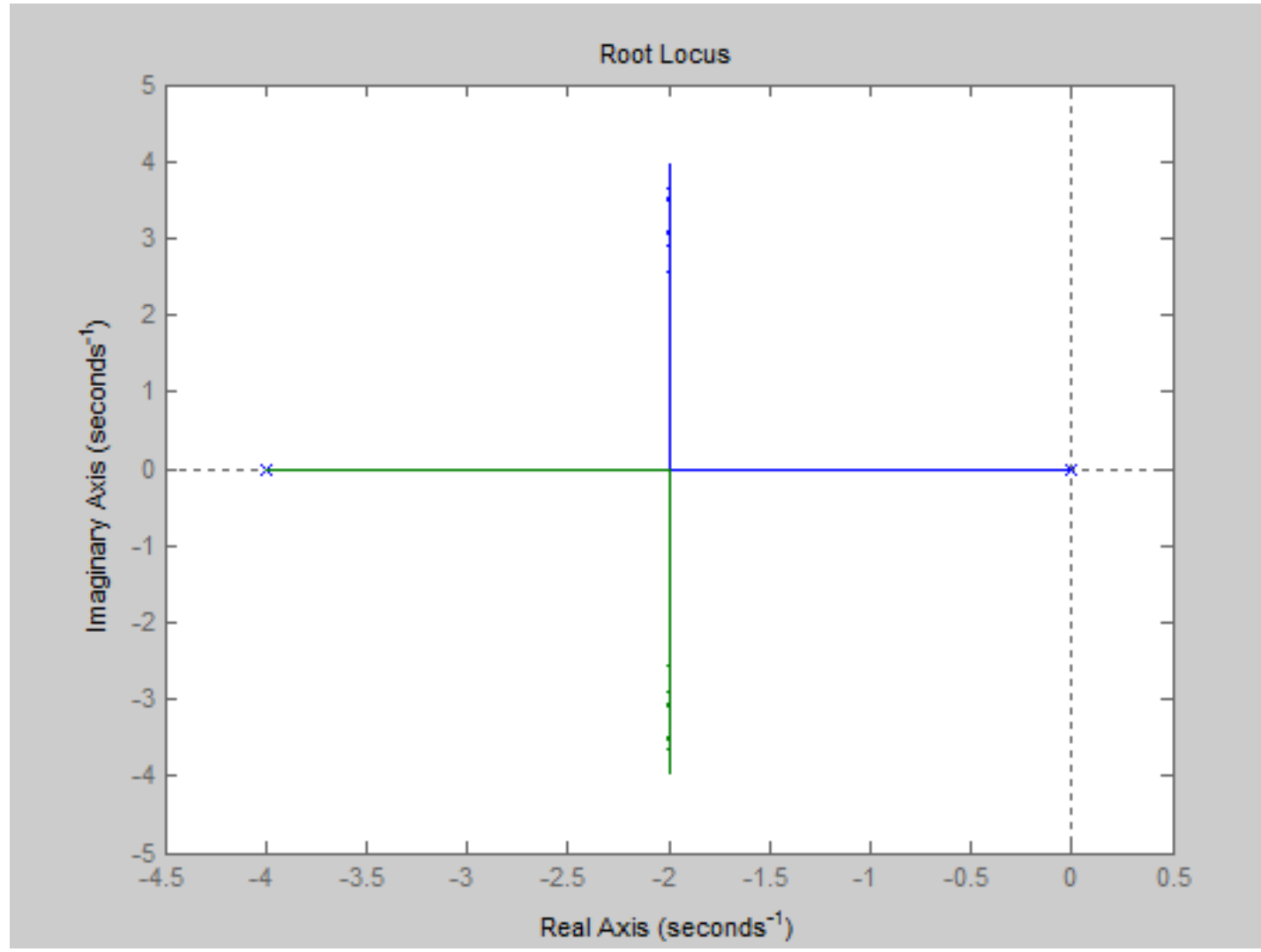

Fonte: Autoria própria.

Portanto, observa-se que o valor de Kp depende do coeficiente de amortecimento zeta, e ambos definem o tipo de sistema encontrado (subamortecido, criticamente amortecido ou sobreamortecido). O sistema subamortecido é o mais oscilatório deles, conforme já mencionado em definições anteriores.

\subsubsection{CONTROLADOR PROPORCIONAL-INTEGRAL}

A Figura 12 mostra o diagrama de blocos em função de $\mathrm{Kp}$ e $\mathrm{Ki}$, que corresponde ao controlador proporcional-integral. 


\section{Figura 12 - Modelo com controlador PI}

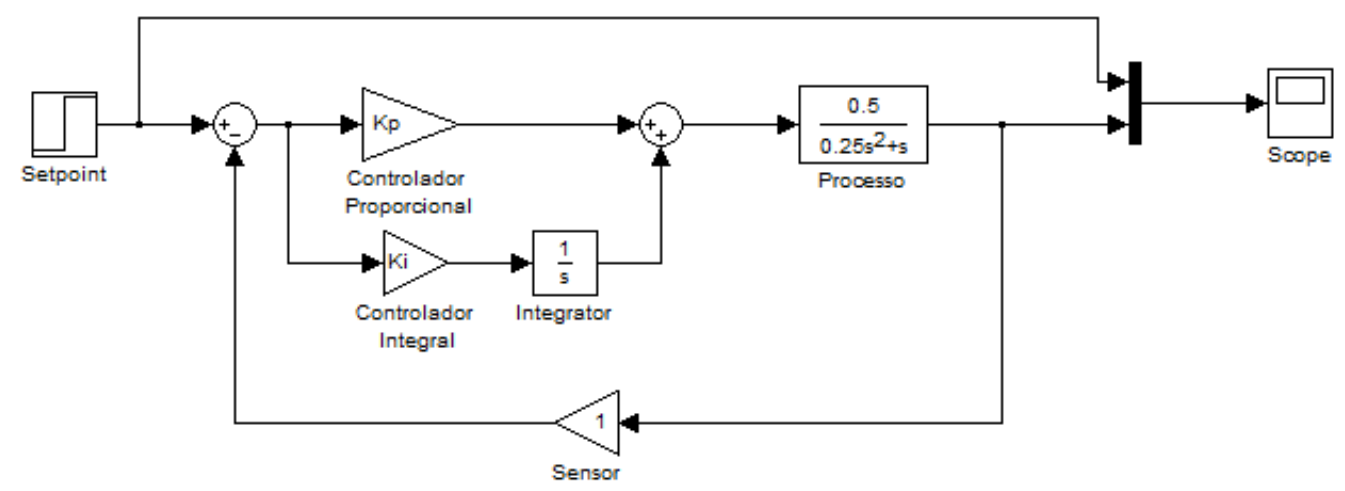

Fonte: Autoria própria.

A função de transferência para o modelo com controlador proporcional da Figura 12 é:

$$
\frac{C(s)}{R(s)}=\frac{\frac{0,5 K p s+0,5 K i}{0,25 s^{3}+s^{2}}}{1+\frac{0,5 K p s+0,5 K i}{0,25 s^{3}+s^{2}}}=\frac{0,5 K p s+0,5 K i}{0,25 s^{3}+s^{2}+0,5 K p s+0,5 K i}
$$

A equação característica do sistema é:

$$
0,25 s^{3}+s^{2}+0,5 K p s+0,5 K i=0
$$

A Figura 13 mostra a simulação em diagrama de blocos do sistema de controle de malha fechada, para três valores de Kp e de Ki, com a finalidade de verificar quais os valores mais adequados e eficazes para atuação como controladores proporcional e integrativo, respectivamente. Na Figura 14 é apresentado o gráfico obtido a partir desta simulação de resposta ao degrau. 


\section{Figura 13 - Simulação de resposta ao controlador PI}

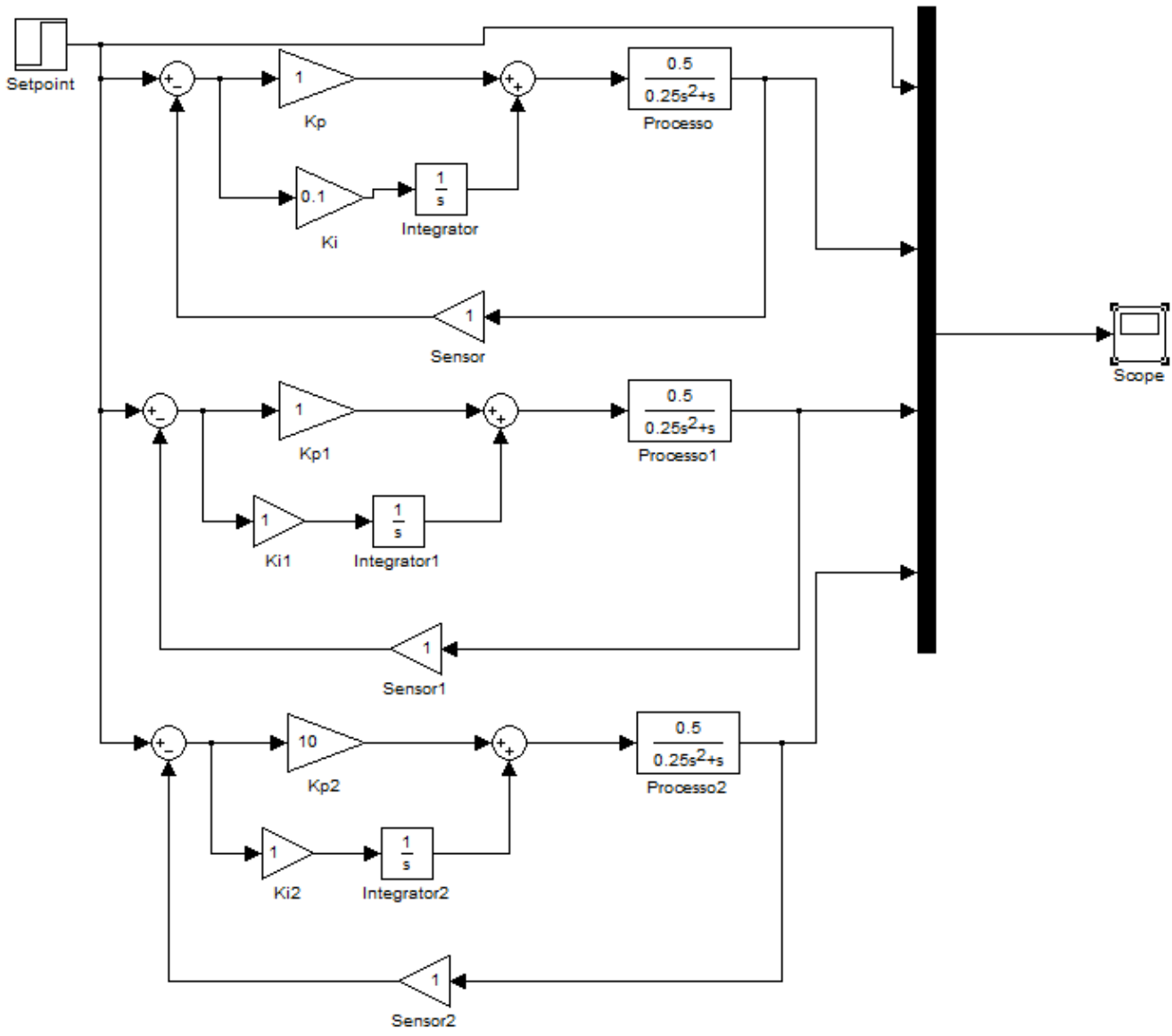

Fonte: Autoria própria.

Figura 14 - Gráfico de resposta ao controlador PI

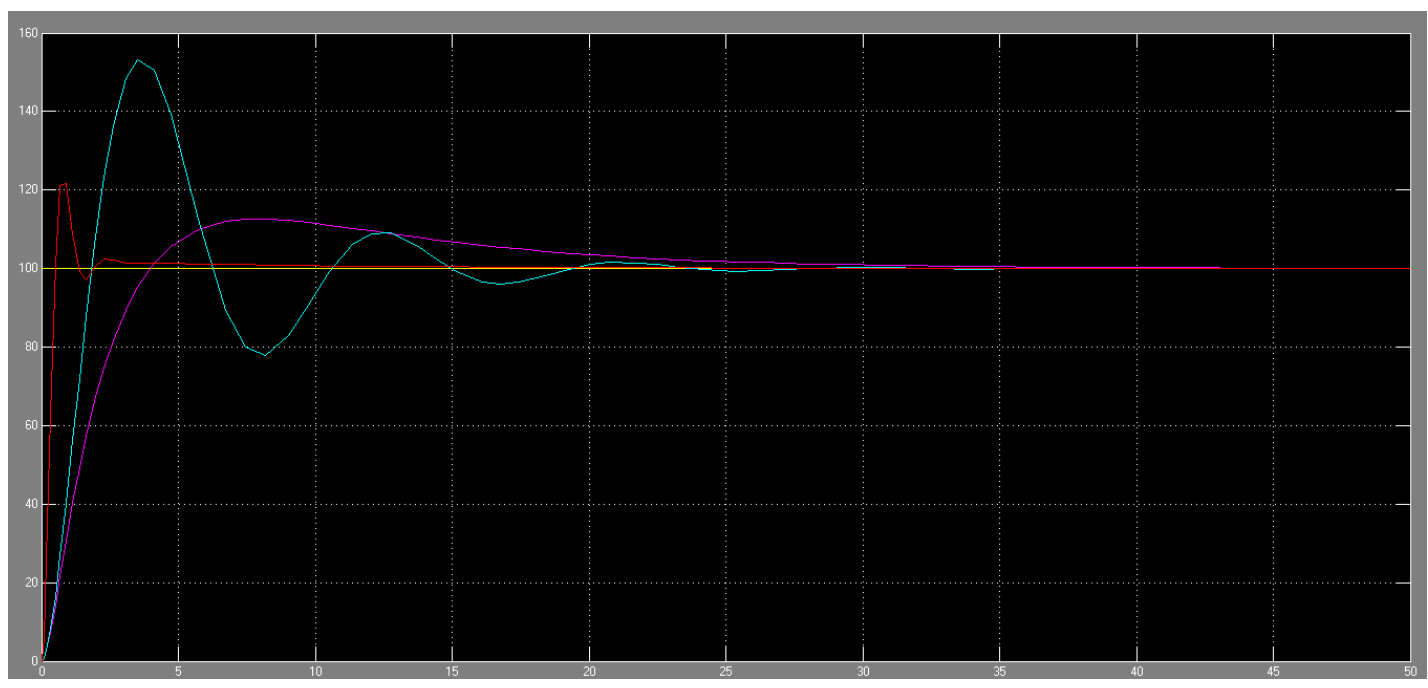

Fonte: Autoria própria.

Dessa maneira:

- A reta horizontal do gráfico representa a entrada do sistema com amplitude 100. 
- A primeira curva (em vermelho) do gráfico representa a resposta ao degrau para $\mathrm{Kp}=10$ e $\mathrm{Ki}=1$. Substituindo estes valores na função de transferência acima, são encontradas duas raízes como complexos conjugados: $-1.95+3,98 \mathrm{i},-1.95-3,98 \mathrm{i}$, e uma raiz real: -0.1 .

- A segunda curva (em azul) do gráfico representa a resposta ao degrau para $\mathrm{Kp}=1$ e Ki $=1$. Substituindo estes valores na função de transferência acima, obtém-se uma raiz real $-3,75$ e duas raízes como complexos conjugados: $-0.12+\mathrm{i},-0.12-\mathrm{i}$.

- A terceira curva (em lilás) do gráfico representa a resposta ao degrau para Kp $=1$ e Ki $=0,1$. Substituindo estes valores na função de transferência acima, são encontradas três raízes reais: $-3.4,-0.4$ e -0.1 .

Além disso, este sistema monitorado por controlador proporcional-integral foi analisado pelo método do lugar das raízes, cujo gráfico pode ser visualizado na Figura 15.

Figura 15 - Gráfico do lugar das raízes para controlador PI

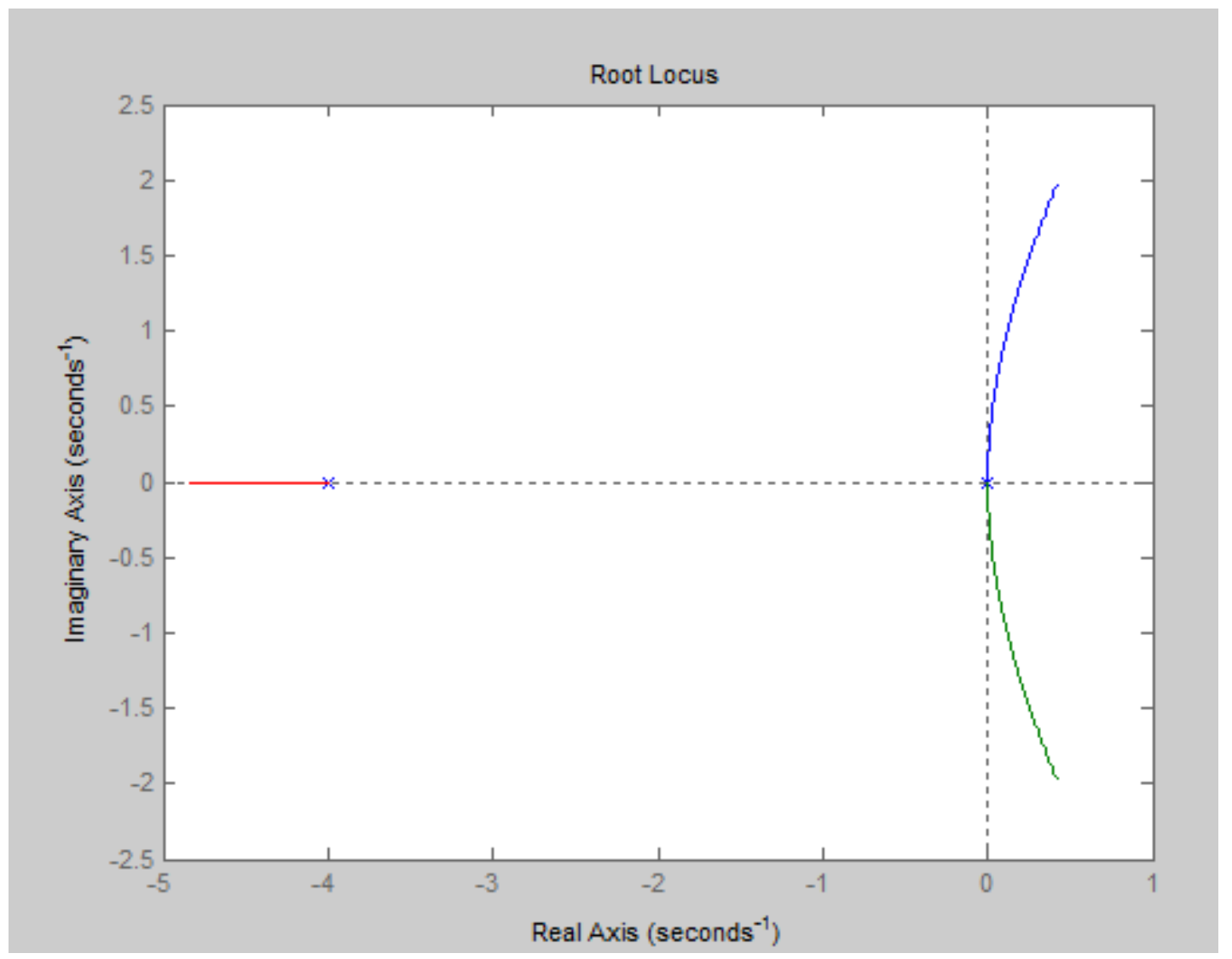

Fonte: Autoria própria.

Logo, observa-se que este controle utiliza um integrador como controlador. O integrador é um circuito que executa a operação matemática da integração, que pode ser descrita como o somatório dos produtos dos valores instantâneos da grandeza de entrada por pequenos intervalos de tempo, desde o instante inicial até o final (período de integração). Isso corresponde à área entre a curva da grandeza e o eixo do tempo em um gráfico. 
$\mathrm{O}$ uso do integrador como controlador faz com que o sistema fique mais lento, pois a resposta dependerá da acumulação do sinal de erro na entrada, mas leva a um erro de regime nulo, pois não é necessário um sinal de entrada para haver saída do controlador, e acionamento do atuador após o período transitório. Assim o controle é muito preciso, embora mais lento.

\subsubsection{CONTROLADOR PROPORCIONAL-DERIVATIVO}

A Figura 16 mostra o diagrama de blocos em função de $\mathrm{Kp}$ e $\mathrm{Kd}$, que corresponde ao controlador proporcional-derivativo.

\section{Figura 16 - Modelo com controlador PD}

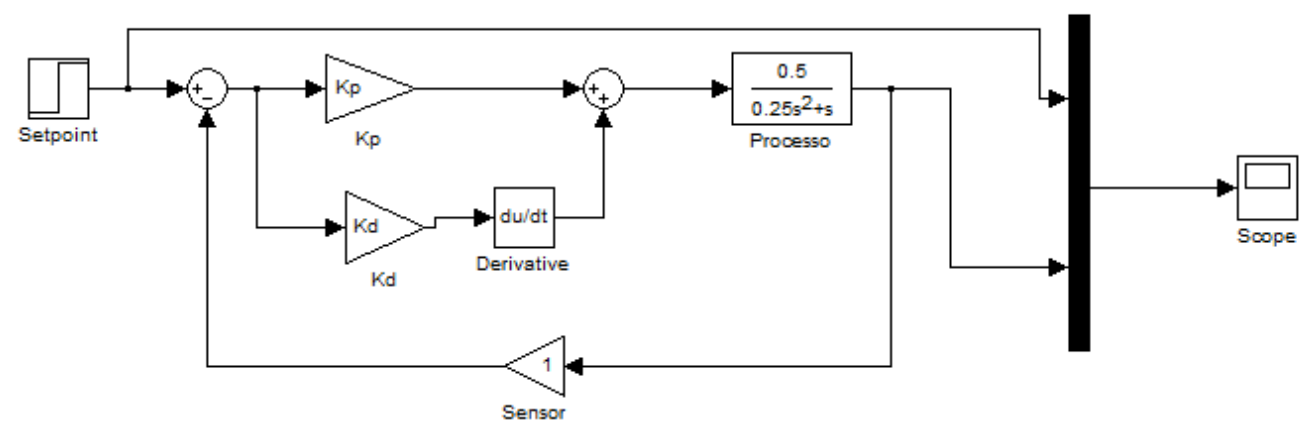

Fonte: Autoria própria.

A função de transferência para o modelo com controlador proporcional da Figura 16 é:

$$
\frac{C(s)}{R(s)}=\frac{\frac{0,5 K p+0,5 K d s}{0,25 s^{2}+s}}{1+\frac{0,5 K p+0,5 K d s}{0,25 s^{2}+s}}=\frac{0,5 K d s+0,5 K p}{0,25 s^{2}+s+0,5 K d s+0,5 K p}
$$

A equação característica do sistema é:

$$
0,25 s^{2}+s+0,5 K d s+0,5 K p=0
$$

A Figura 17 mostra a simulação em diagrama de blocos do sistema de controle de malha fechada, para três valores de Kp e de Kd, com a finalidade de verificar quais os valores mais adequados e eficazes para atuação como controladores proporcional e derivativo, respectivamente. Na Figura 18 é apresentado o gráfico obtido a partir dessa simulação de resposta ao degrau. 
Figura 17 - Simulação de resposta ao controlador PD

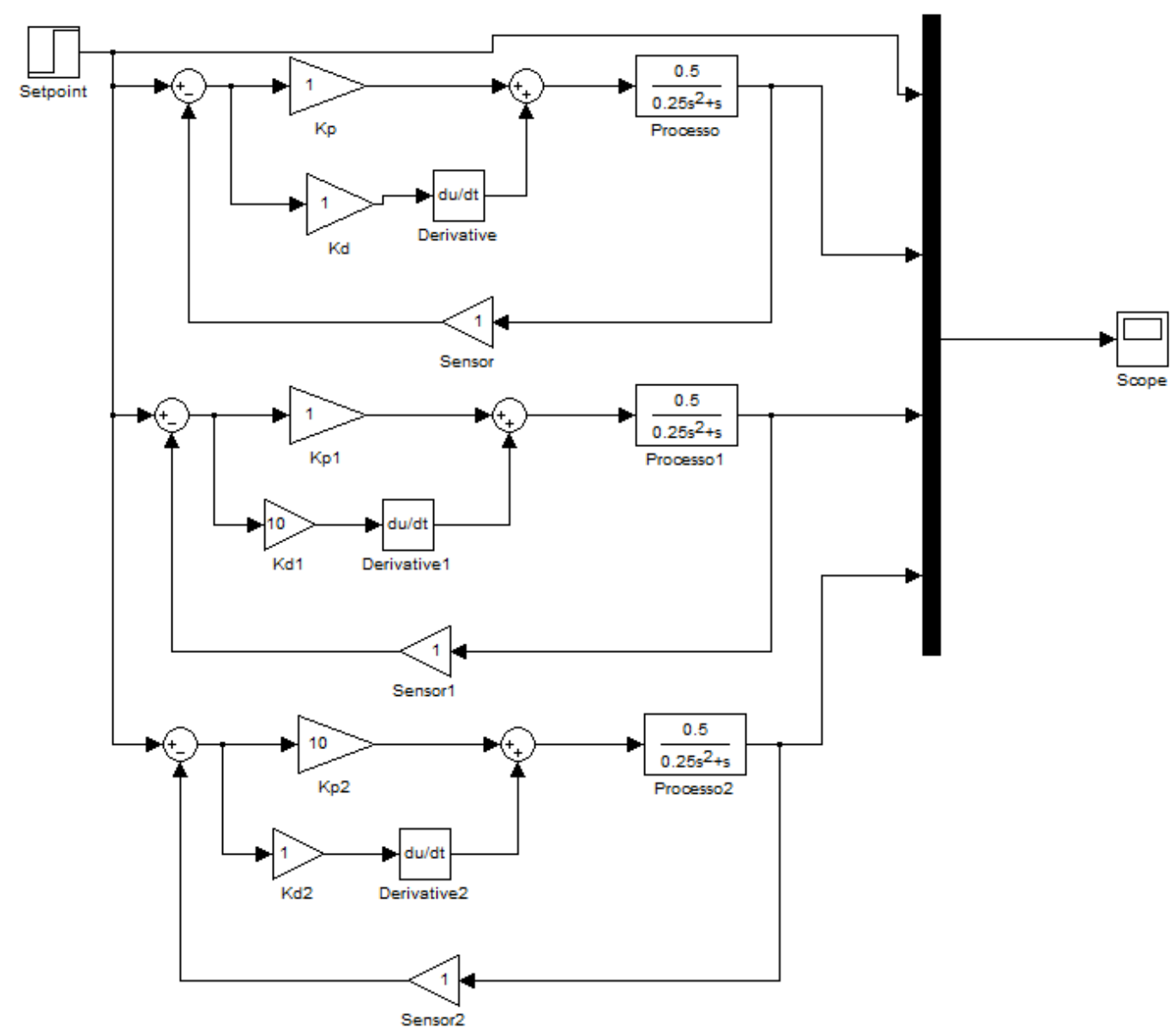

Fonte: Autoria própria.

Figura 18 - Gráfico de resposta ao controlador PD

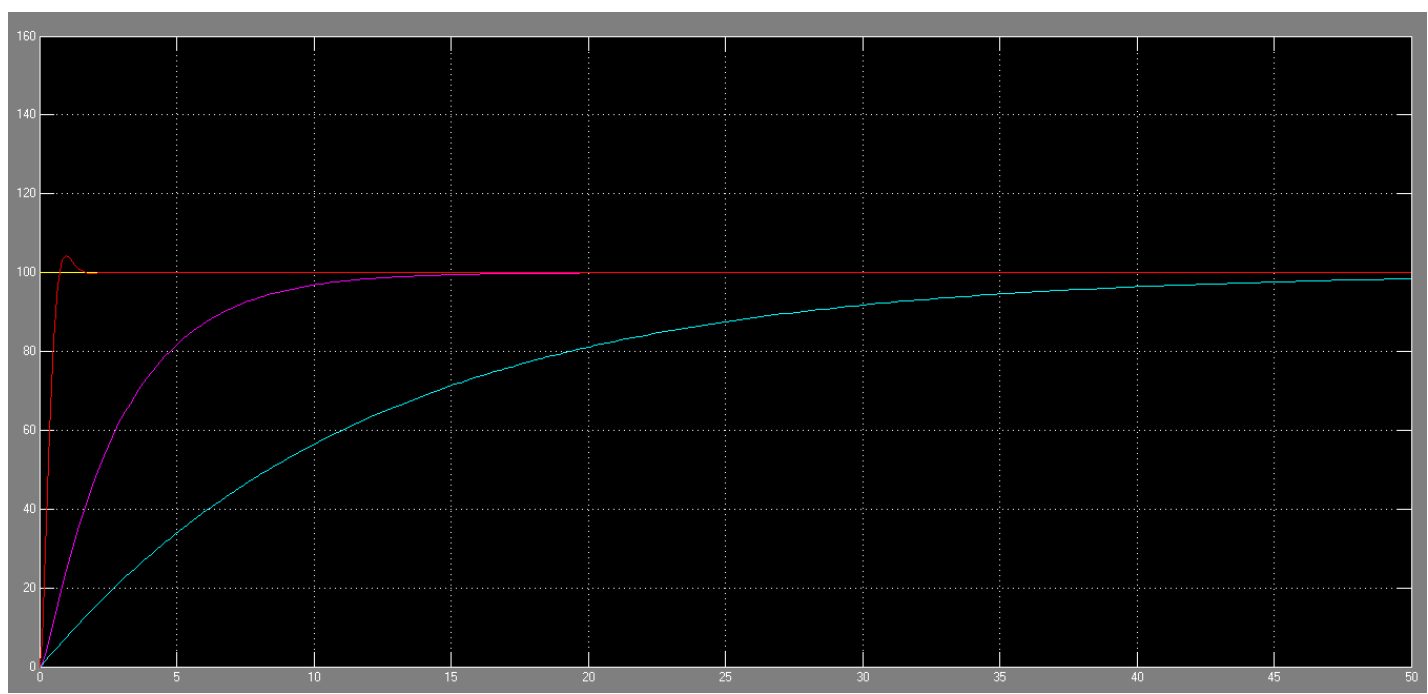

Fonte: Autoria própria.

Dessa maneira:

- A reta horizontal do gráfico representa a entrada do sistema com amplitude 100. 
- A primeira curva (em vermelho) do gráfico representa a resposta ao degrau para $\mathrm{Kp}=10$ e $\mathrm{Ki}=1$. Substituindo estes valores na função de transferência acima, são encontradas duas raízes como complexos conjugados: $-3+3,32 \mathrm{i},-3-3,32 \mathrm{i}$.

- A segunda curva (em lilás) do gráfico representa a resposta ao degrau para $\mathrm{Kp}=1 \mathrm{e}$ $\mathrm{Kd}=1$. Substituindo estes valores na função de transferência acima, são encontradas duas raízes reais: $-5,65$ e $-0,35$.

- A terceira curva (em azul) do gráfico representa a resposta ao degrau para $\mathrm{Kp}=1 \mathrm{e}$ $\mathrm{Ki}=10$. Substituindo estes valores na função de transferência acima, são encontradas duas raízes reais: $-23,92$ e $-0,08$.

Além disso, esse sistema monitorado por controlador proporcional-derivativo foi analisado pelo método do lugar das raízes, cujo gráfico pode ser visualizado na Figura 19.

\section{Figura 19 - Gráfico do lugar das raízes para controlador PD}

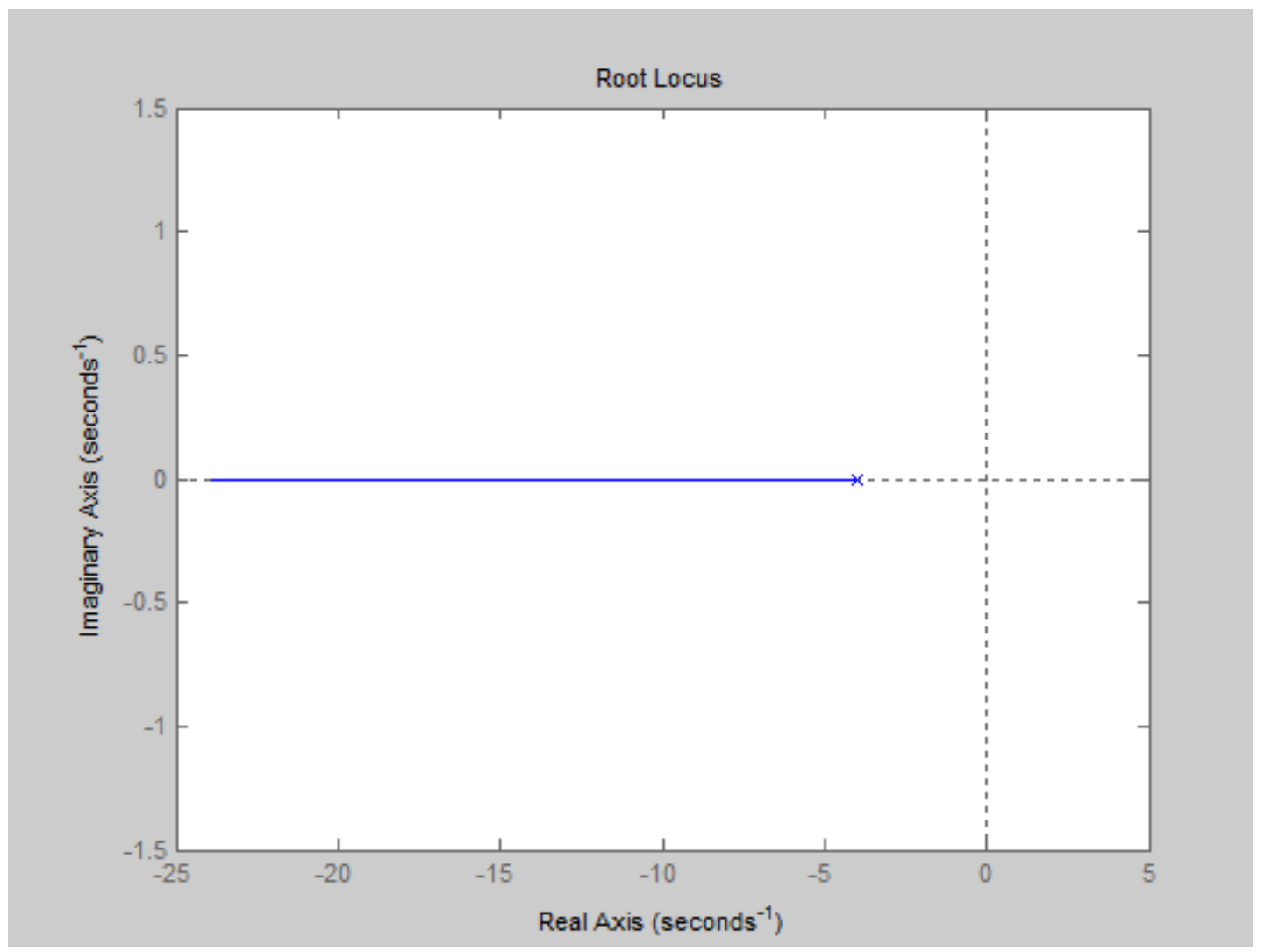

Fonte: Autoria própria.

Portanto, pode-se concluir que com o aumento do Kd para pólos reais o tempo de acomodação do sistema aumenta. O controle derivativo, apesar de sensível a sinais de alta frequência, melhora a estabilidade do sistema, reduzindo overshoots e amortecendo oscilações, além de produzir efeitos de antecipação nas correções.

$\mathrm{Na}$ teoria de controle, o overshoot refere-se à uma saída que excede seu valor final de estado estacionário. Para uma entrada por degrau, o percentual do overshoot (PO) é o valor máximo menos o valor do degrau dividido pelo valor do degrau (OGATA, 2011). 
Para eliminar o problema do overshoot é introduzido um termo derivativo correspondendo a taxa de mudança do erro. Esse fator faz com que o controlador tenha uma resposta inicial elevada e diretamente relacionada à taxa de mudança do erro. Quanto maior a taxa de mudança do erro mais rápida é a resposta do controlador à mudança. $\mathrm{O}$ controle derivativo é insensível a erros constantes ou de variação lenta, e consequentemente não é usado sozinho, mas combinado com outras formas de controle. A ação derivativa quando combinada com a ação proporcional tem justamente a função de "antecipar"a ação de controle a fim de que o processo reaja mais rápido. O controle derivativo, apesar de sensível a sinais de alta frequência, melhora a estabilidade do sistema, reduzindo overshoots e amortecendo oscilações, além de produzir efeitos de antecipação nas correções. A ação proporcional produz o efeito de reduzir o tempo de subida, e apenas reduz o erro de regime sem eliminá-lo.

\subsubsection{CONTROLADOR PROPORCIONAL-INTEGRAL-DERIVATIVO}

A Figura 20 mostra o diagrama de blocos em função de Kp, Ki e Kd, que corresponde ao controlador proporcional-integral-derivativo.

Figura 20 - Modelo com controlador PID

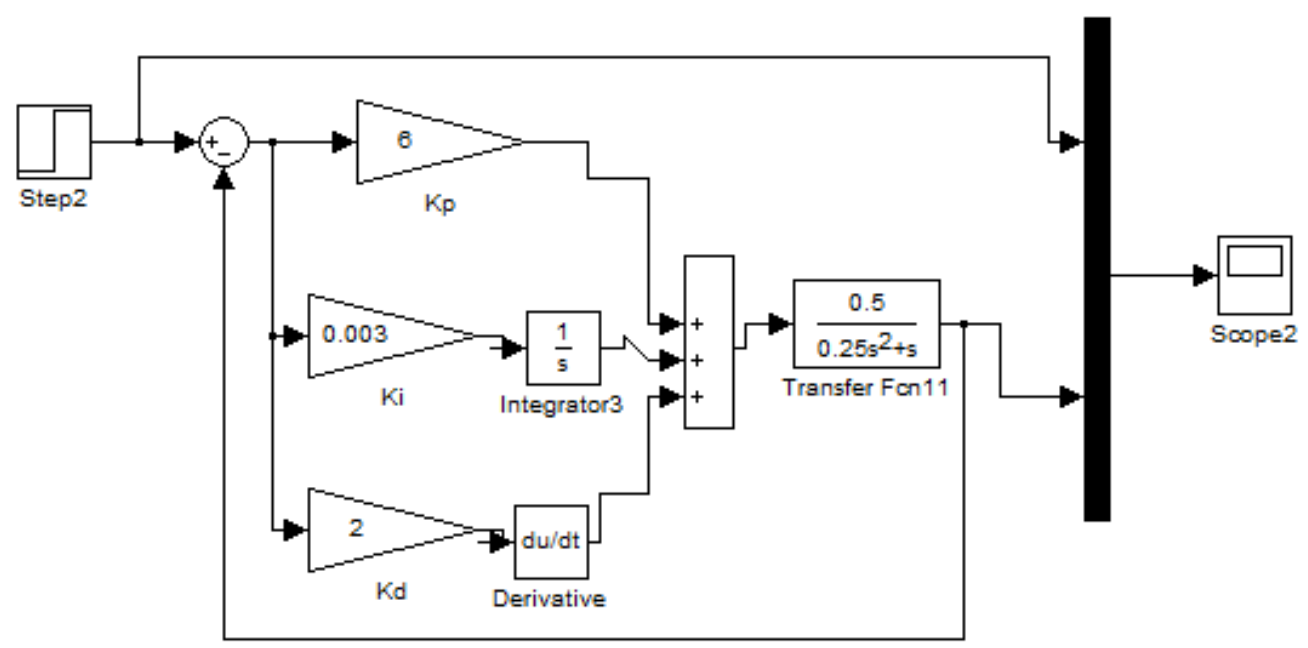

Fonte: Autoria própria.

A partir de simulações efetuadas com o sistema de controle PID apresentado na Figura 20, o melhor ajuste possível para que a esteira seja mantida em velocidade constante, sem oscilação, é o representado no gráfico da Figura 21, em que $\mathrm{Kp}=6, \mathrm{Ki}=0,003$ e Kd=2. 
Figura 21 - Gráfico de resposta ao controlador PID

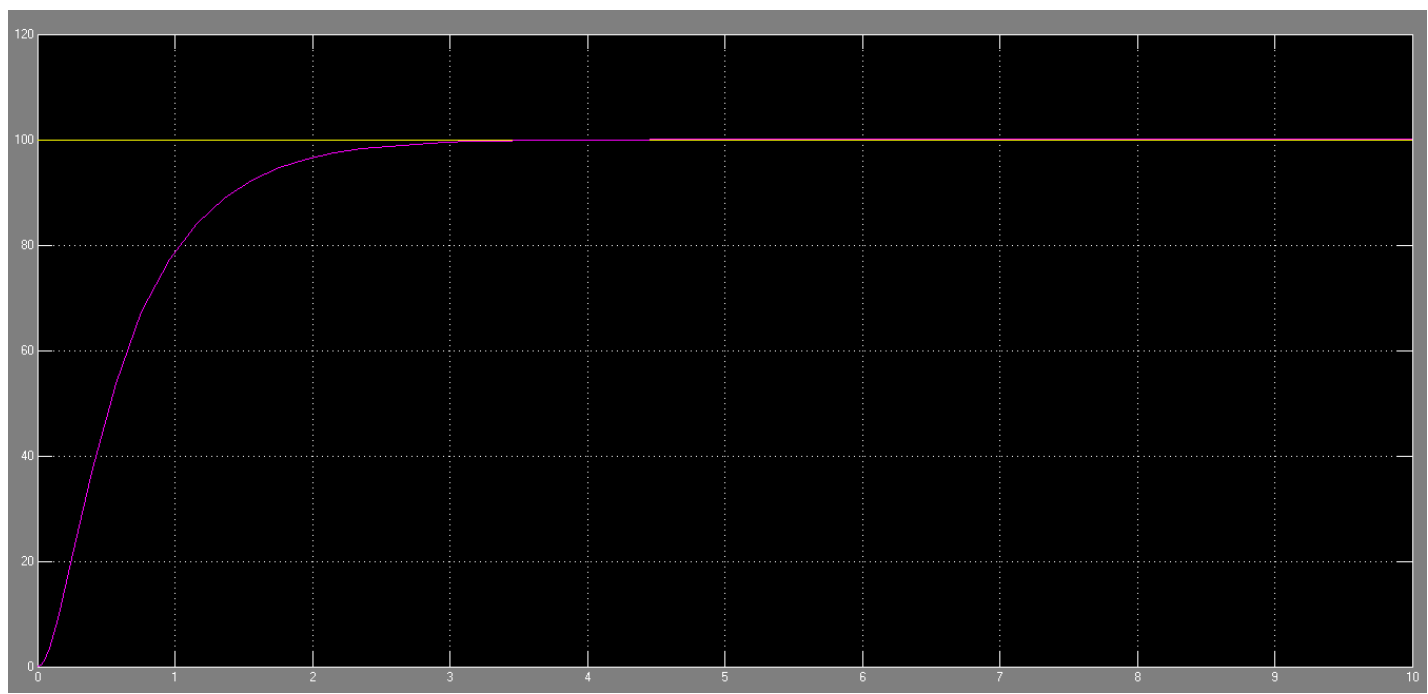

Fonte: Autoria própria.

Portanto, observa-se que em um sistema de controle de malha fechada com ações do tipo PID, a ação proporcional produz o efeito de reduzir o tempo de subida, e apenas reduz o erro de regime sem eliminá-lo. Já o controle integral elimina o erro de regime, porém piora a resposta transitória tornando-a mais oscilatória. O controle derivativo, apesar de sensível a sinais de alta frequência, melhora a estabilidade do sistema, reduzindo overshoots e amortecendo oscilações, além de produzir efeitos de antecipação nas correções. Os efeitos de $\mathrm{Kp}$, Ki, e Kd são dependentes um do outro, isto é, a variação de um desses parâmetros de controle pode mudar o efeito dos outros dois sobre o sistema, conforme pode ser visto no Quadro 1.

\section{Quadro 1 - Componentes do questionário aplicado na pesquisa}

\begin{tabular}{|l|l|l|l|l|}
\hline & $\begin{array}{l}\text { Tempo de } \\
\text { subida }\end{array}$ & Overshoot & $\begin{array}{l}\text { Tempo de } \\
\text { acomodação }\end{array}$ & $\begin{array}{l}\text { Erro } \\
\text { estacionário }\end{array}$ \\
\hline Kp & Diminui & Aumenta & $\begin{array}{l}\text { Pouca } \\
\text { Influência }\end{array}$ & Diminui \\
\hline Ki & Diminui & Aumenta & Aumenta & Elimina \\
\hline Kd & $\begin{array}{l}\text { Pouca } \\
\text { influência }\end{array}$ & Diminui & Diminui & $\begin{array}{l}\text { Pouca } \\
\text { influência }\end{array}$ \\
\hline
\end{tabular}

Fonte: Adaptado de Ogata (2011).

\subsubsection{ANÁLISE PELO MODELO DO SISTEMA DE SEGUNDA ORDEM}

A Figura 22 apresenta a simulação do sistema de $1^{\mathrm{a}}$ e de $2^{\mathrm{a}}$ ordem, com controlador proporcional-integral-derivativo (PID) em malha fechada. 


\section{Figura 22 - Modelo de segunda ordem com controlador PID}

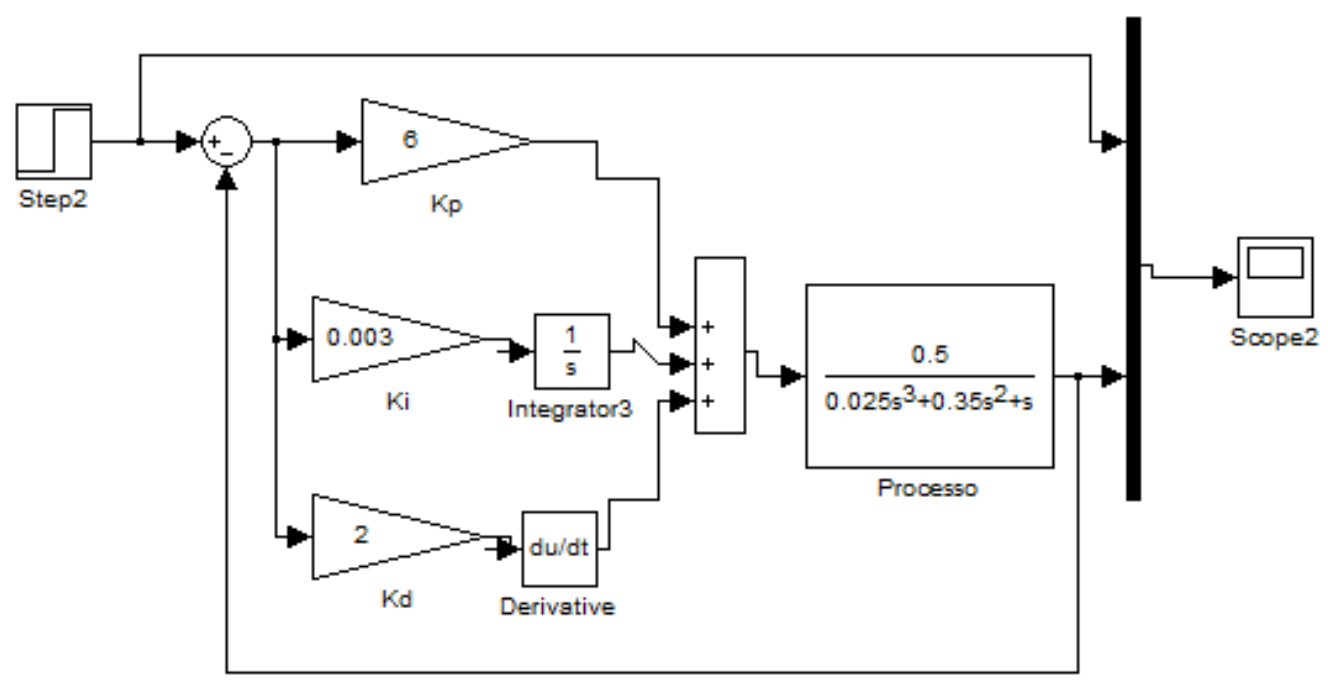

Fonte: Autoria própria.

A Figura 23 mostra a resposta do sistema referente à simulação com controlador proporcional-integral-derivativo em malha fechada da Figura 22. A curva em formato linear (a reta horizontal) corresponde ao controle de $1^{\mathrm{a}}$ ordem e a outra curva refere-se ao controle de $2^{\mathrm{a}}$ ordem (em lilás).

Figura 23 - Gráfico de resposta ao modelo de segunda ordem

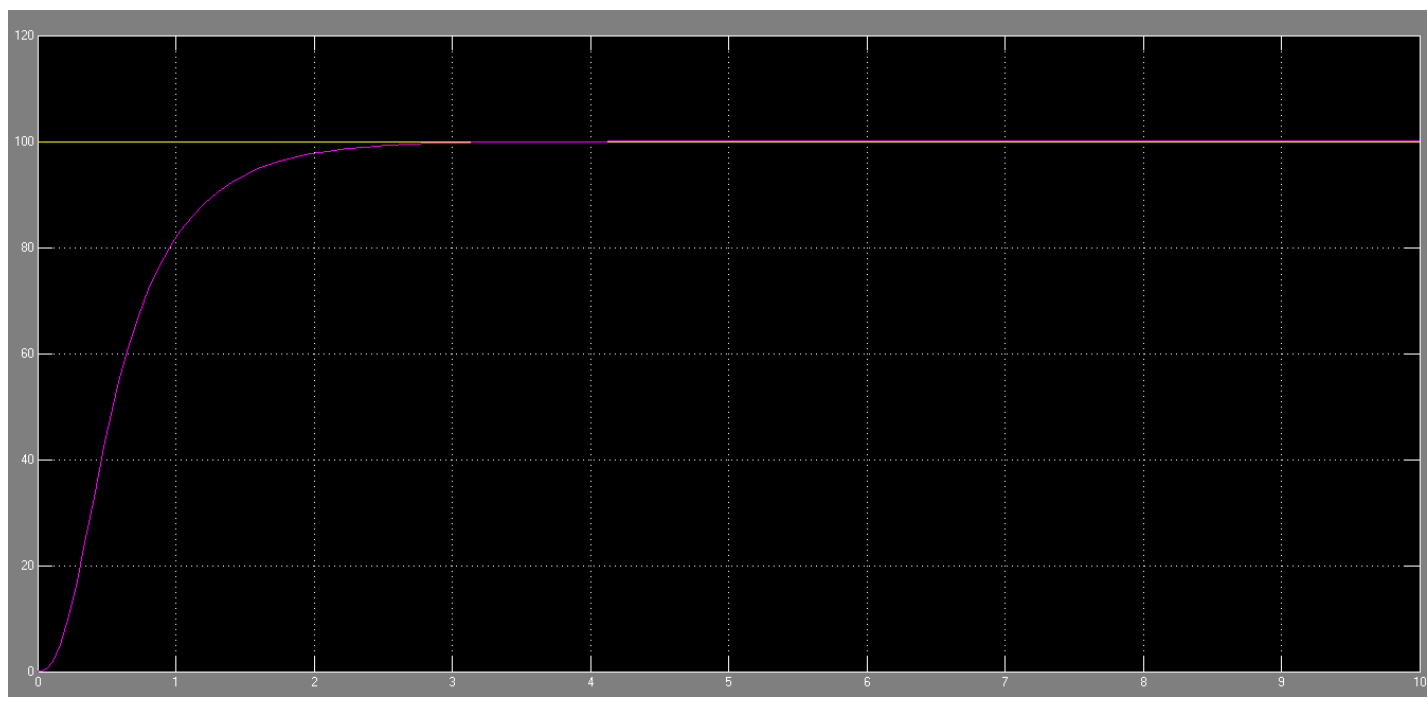

Fonte: Autoria própria.

Pode-se concluir que alterando o sistema PID para de segunda ordem, a resposta ao degrau do sistema é parecida com a resposta ao sistema de primeira ordem realizado anteriormente, para os valores adotados para $\mathrm{Kp}, \mathrm{Ki}$ e $\mathrm{Kd}$ anteriormente. 


\section{CONSIDERAÇÕES FINAIS}

De acordo com o que foi mencionado anteriormente, o objetivo deste trabalho consistiu em desenvolver um sistema de controle para a velocidade de uma esteira transportadora industrial de maneira que o sistema de bombeamento consiga manter uma taxa de vazão qi constante, e o motor DC acione a esteira suprindo a vazão de saída qo para alimentar a usina de processamento. Além disso, inseriu-se um controlador com ações independentes no sistema, do tipo proporcional (P), proporcional-integral (PI), proporcional-derivativo (PD) e proporcionalintegral-derivativo (PID), apresentando o desempenho do sistema para cada um dos casos e as respectivas conclusões.

Em virtude do que foi investigado, percebe-se que o controlador proporcional combina as vantagens do controlador PI e PD. A ação integral está diretamente ligada à precisão do sistema sendo responsável pelo erro nulo em regime permanente. O efeito desestabilizador do controlador PI é contrabalançado pela ação derivativa que tende a aumentar a estabilidade relativa do sistema, ao mesmo tempo que torna a resposta do sistema mais rápida devido ao seu efeito antecipatório.

Logo, o efeito final é que o sinal de erro seja minimizado pela ação proporcional, zerado pela ação integral e obtido com uma velocidade antecipativa pela ação derivativa, afim de, atender o melhor ajuste possível da velocidade da esteira que neste trabalho foi encontrada. Assim, o controlador PID atendeu as especificações desse sistema de controle. 


\section{REFERÊNCIAS}

BEGA, E. A. Instrumentação industrial. 2. ed. Rio de Janeiro: Interciência, 2006.

BINGHAM, J; DAVIES, G. W. P. E. Manual de análise de sistemas. Rio de Janeiro: Interciência, 2007.

CHAPMAN, S. J. Programação em MATLAB para engenheiros. São Paulo: Thomson, 2003.

DIAS, J. H.; LIMA, A. S.; TOSTES, M. E. Uso do método lqg-ltr para o controle de velocidade em transportadores de correia visando a eficiência energética. In: CONFERÊNCIA INTERNACIONAL DE APLICAÇÕES INDUSTRIAIS, 8., 2008, POÇOS DE CALDAS, 2008. Anais[...]. Poços de Caldas: Universidade de São Paulo, 2008.

DIAS, S. V. Controle de velocidade de uma correia transportadora utilizando controlador pi. In: ENCONTRO DE PESQUISA E PÓS-GRADUAÇÃO, 9., 2012. Anais[...]. Fortaleza: Universidade Federal do Ceará, 2012.

FIALHO, A. B. Instrumentação industrial: conceitos, aplicações e análises. 6. ed. São paulo: Érica, 2012.

FREITAS, E. J. de R. et al. Controle de velocidade de uma esteira transportadora. In: INTERNATIONAL CONFERENCE ON ENGINEERING AND COMPUTER EDUCATION, 8, 2013. Proceedings[...]. Luanda: Universidade de Angola, 2013. p. 154-158.

LEONARDI, F. Controle Essencial. São Paulo: Pearson, 2010.

NISE, N. S. Engenharia de Sistemas de Controle. 3. ed. Rio de Janeiro: LTC, 2002.

NOGUEIRA, F. J. H. Correias Transportadoras - Guia Avançado. Procel indústria. Rio de Janeiro: [s.n.], 2004.

OGATA, K. Engenharia de controle moderno. São Paulo: Pearson, 2011.

RANIEL, T. Desenvolvimento e Implementação de um Sistema de Controle de Posição e Velocidade de uma Esteira Transportadora usando Inversor de Frequência e Microcontrolador. 2011. Dissertação (Mestrado) — Programa de Pós-Graduação em Engenharia Elétrica - Universidade Estadual Paulista "Júlio de Mesquita Filho", Ilha Solteira, 2011. 